\title{
STRUCTURE AND PROPERTIES OF STRONTIUM-ZINC BOROPHOSPHATE GLASSES
}

\author{
LADISLAV KOUDELKA, PETR MOŠNER and PETRA PROK $\square$ PKOVÁ \\ Department of General and Inorganic Chemistry \\ Faculty of Chemical Technology \\ University of Pardubice, 53210 Pardubice, Czech Republic
}

\begin{abstract}
Borophosphate glasses of the $\mathrm{SrO}-\mathrm{ZnO}-\mathrm{B}_{2} \mathrm{O}_{3}-\mathrm{P}_{2} \mathrm{O}_{5}$ system were studied in two compositional series with a constant $\mathrm{MO}$ or $\mathrm{B}_{2} \mathrm{O}_{3} / \mathrm{P}_{2} \mathrm{O}_{5}$ content. The effect of compositional changes on the physical properties of the glasses was investigated. The replacement of $\mathrm{Zn}$ by $\mathrm{Sr}$ results in a more tight structure of the glass. Raman spectra of the glasses with an increasing $\mathrm{B}_{2} \mathrm{O}_{3} / \mathrm{P}_{2} \mathrm{O}_{5}$ content reflect a gradual transformation from the chain-like structure to the three dimensional structure with isolated $\mathrm{PO}_{4}$ tetrahedra in the glasses with a low $\mathrm{B}_{2} \mathrm{O}_{3}$ content.
\end{abstract}

\section{INTRODUCTION}

Borophosphate glasses were recently belong to interesting glassy materials, e.g.zinc-calcium borophosphate glasses were studied as candidates for applications as low-melting glass solders or glass seals ${ }^{1,2}$. The structure and properties of borophosphate glasses were studied mostly on the borophosphates with alkali ions, the data on the borophosphates of the other elements are not so numerous. The XPS, NMR and Raman structural studies of $\mathrm{Zn}$ borophosphates were reported by Brow et al. ${ }^{3,4}$ for the compositional series of $\mathrm{Zn}\left(\mathrm{PO}_{3}\right)_{2}-\mathrm{B}_{2} \mathrm{O}_{3}$ and $\mathrm{ZnP}_{2} \mathrm{O}_{7}-\mathrm{B}_{2} \mathrm{O}_{3}$. Recently we have studied the properties of glasses in the $\mathrm{ZnO}-\mathrm{B}_{2} \mathrm{O}_{3}-\mathrm{P}_{2} \mathrm{O}_{5}$ system ${ }^{5,6}$.

\section{EXPERIMENTAL PROCEDURE}

Samples of the $\mathrm{xZnO}-\mathrm{ySrO}-\mathrm{zB}_{2} \mathrm{O}_{3}-\mathrm{uP}_{2} \mathrm{O}_{5}$ were prepared by mixing $\mathrm{ZnO}, \mathrm{SrCO}_{3}$, $\mathrm{H}_{3} \mathrm{BO}_{3}$ in an achate mortar and adding $\mathrm{H}_{3} \mathrm{PO}_{4}$ in the proper stoichiometric ratio and by subsequent drying and heating slowly the reaction mixture up to $1200-1250^{\circ} \mathrm{C}$ in a $\mathrm{Pt}$ 
crucible. After 30 min treatment and mixing at this temperature the obtained melt was cooled by pouring on a steel plate.

Thermomechanical properties of glasses were measured on the equipment TMA CX04R (RMI Pardubice) at the heating rate of $5 \mathrm{~K} / \mathrm{min}$. The linear coefficient of thermal expansion $(\alpha)$ was obtained as a mean value in the temperature range of $50-150^{\circ} \mathrm{C}$. The glass transition temperature $\left(\mathrm{T}_{\mathrm{g}}\right)$ was determined from the change in the slope of the elongation versus temperature plot. The dilatation softening temperature $\left(T_{D}\right)$ was obtained from the maximum of the expansion trace. Thermal behaviour of the glasses was also studied by differential thermal analysis with Perkin-Elmer DTA 1700.

Raman spectra on the bulk samples were obtained with a FT IR spectrometer, Bruker model IFS 55, with the Raman attachment, FRA 106, at room temperature under excitation with the Nd:YAG laser radiation using a slit width of $4 \mathrm{~cm}^{-1}$ with a power on the sample of $90 \mathrm{~mW}$ and 400 scans. Infrared spectra were recorded with an IR spectrometer, Perkin-Elmer 684, with the powder samples dispersed in nujol mulls.

\section{RESULTS AND DISCUSSION}

The samples of the $\mathrm{ZnO}-\mathrm{SrO}-\mathrm{B}_{2} \mathrm{O}_{3}-\mathrm{P}_{2} \mathrm{O}_{5}$ system were studied in 2 compositional series of (A) $25 \mathrm{ZnO}-25 \mathrm{SrO}-\mathrm{xB}_{2} \mathrm{O}_{3}-(50-\mathrm{x}) \mathrm{P}_{2} \mathrm{O}_{5}$ and (B) $(50-\mathrm{x}) \mathrm{ZnO}-\mathrm{xSrO}-20 \mathrm{~B}_{2} \mathrm{O}_{3}-$ $30 \mathrm{P}_{2} \mathrm{O}_{5}$. Prepared samples were checked visually for homogeneity. The phase-separated glass was obtained in the first series of glasses only at the composition with $x=30$ mol. $\% \mathrm{~B}_{2} \mathrm{O}_{3}$. The composition of the obtained homogeneous glasses is given in Table 1 together with the determined values of density $(\rho)$ of the glasses and the molar volume $\left(V_{M}\right)$ calculated from the values of density. In the series $A$ the density slightly increases with the replacement of $\mathrm{P}_{2} \mathrm{O}_{5}$ by $\mathrm{B}_{2} \mathrm{O}_{3}$ and the molar volume decreases. In the series $\mathrm{B}$ the replacement of $\mathrm{Zn}$ by $\mathrm{Sr}$ results in a slight increase both in density and molar volume with the replacement of lighter and smaller $\mathrm{Zn}$ atoms by bulky and heavy $\mathrm{Sr}$ atoms. It seems that the replacement of zinc atoms by strontium atoms in the borophosphate network results in a more compact structure of the glass.

We have tested also the solubility of the glasses in the distilled water, but we have not registered any weight loss after $24 \mathrm{hr}$ of contact of the test specimens with water. 
TABLE 1 Composition, density $(\rho)$, molar volume $\left(\mathrm{V}_{\mathrm{M}}\right)$, glass transition temperature $\left(\mathrm{T}_{\mathrm{g}}\right)$ dilatation softening temperature $\left(\mathrm{T}_{\mathrm{d}}\right)$ and the thermal expansion coefficient $(\alpha)$ of glasses of the $\mathrm{ZnO}-\mathrm{SrO}-\mathrm{B}_{2} \mathrm{O}_{3}-\mathrm{P}_{2} \mathrm{O}_{5}$ system.

\begin{tabular}{|c|c|c|c|c|c|c|c|c|c|}
\hline \multirow[t]{2}{*}{ Sample } & SrO & $\mathrm{ZnO}$ & $\mathbf{B}_{2} \mathbf{O}_{3}$ & $\mathbf{P}_{2} \mathbf{O}_{5}$ & \multirow{2}{*}{$\begin{array}{c}\rho \\
{[\text { g.cm }} \\
-3\end{array}$} & \multirow{2}{*}{\begin{tabular}{|c|}
$V_{M}$ \\
{$\left[\mathrm{~cm}^{3}\right]$}
\end{tabular}} & \multirow{2}{*}{$\frac{T_{g}}{\left[{ }^{\circ} \mathrm{C}\right]}$} & \multirow{2}{*}{$\frac{\mathrm{T}_{\mathrm{d}}}{\left[{ }^{\circ} \mathrm{C}\right]}$} & \multirow{2}{*}{$\frac{\alpha}{\left[p p m \cdot K^{-1}\right]}$} \\
\hline & \multicolumn{4}{|c|}{ [mol.\%] } & & & & & \\
\hline $\mathrm{A} 1$ & 25 & 25 & 0 & 50 & 3,05 & 38,5 & 437 & 465 & 7,9 \\
\hline $\mathrm{A} 2$ & 25 & 25 & 10 & 40 & 3,27 & 33,6 & 513 & 537 & 8.0 \\
\hline A3 & 25 & 25 & 20 & 30 & 3,39 & 30,3 & 554 & 574 & 7,5 \\
\hline A4 & 25 & 25 & 30 & 20 & \multicolumn{5}{|c|}{ Phase-separated glass } \\
\hline A5 & 25 & 25 & 40 & 10 & 3,39 & 26,0 & 574 & 605 & 6,6 \\
\hline A6 & 25 & 25 & 50 & 0 & 3,48 & 23,3 & 567 & 592 & 4,3 \\
\hline $\mathrm{B} 1$ & 0 & 50 & 20 & 30 & 3,26 & 29,8 & 492 & 516 & 3,2 \\
\hline $\mathrm{B} 2$ & 12,5 & 37,5 & 20 & 30 & 3,36 & 29,8 & 517 & 539 & 4,2 \\
\hline $\mathrm{B} 3=\mathrm{A} 3$ & 25 & 25 & 20 & 30 & 3,39 & 30,3 & 554 & 574 & 7,5 \\
\hline B4 & 37,5 & 12,5 & 20 & 30 & 3,42 & 30,8 & 593 & 607 & 8,1 \\
\hline
\end{tabular}

Study of $\mathrm{Sr}-\mathrm{Zn}$ borophosphate glasses by thermomechanical analysis gave the values of $\alpha, T_{g}$, and $T_{d}$, given also in Table $I$. Both $T_{g}$ and $T_{d}$ increase abruptly at small additions of $\mathrm{B}_{2} \mathrm{O}_{3}$ and reach a maximum at the glass with $10 \mathrm{~mol} \% \mathrm{~B}_{2} \mathrm{O}_{3}$. These behaviour undoubtedly correspond to some changes in the nature of bonding in the structural network. In the phosphate glasses close to the metaphosphate composition of $\mathrm{Zn}_{0.5} \mathrm{Sr}_{0.5}\left(\mathrm{PO}_{3}\right)_{2}$ the structural network consists of chains of $\mathrm{PO}_{4}$ structural units with 2 bridging and 2 non-bridging oxygen atoms. In the borate glasses trigonal $\mathrm{BO}_{3}$ or tetrahedral $\mathrm{BO}_{4}$ units are formed. $\mathrm{NMR}$ studies ${ }^{4}$ showed that in phosphate-rich glasses tetrahedral $\mathrm{BO}_{4}$ units are preferred. Therefore the incorporation of $\mathrm{BO}_{4}$ units into the chain-like phosphate glass structure results in the transition to the three-dimensional network and thus in an increase of bonding forces within the network.

The replacement of $\mathrm{Zn}$ by $\mathrm{Sr}$ atoms in the borophosphate glasses of the series of $B$ results also in a substantial increase in $T_{g}$ and $T_{d}$ by about $100^{\circ} \mathrm{C}$ for the replacement of $3 / 4$ of $\mathrm{Zn}$ by $\mathrm{Sr}$ atoms (see Table 1). In the glass series $\mathrm{A}$ the values of $\alpha$ are the 
highest at a low boron content $\left(8 \times 10^{-6} \mathrm{ppm} / \mathrm{K}\right)$, but with a further replacement of phosphate groups by borate groups $\alpha$ decreases.

Thermoanalytical study of the behaviour of borophosphate glasses showed at the heating the glasses undergo crystallization within the temperature range of 600$800^{\circ} \mathrm{C}$ mostly in two stages. With an increasing $\mathrm{Sr}$ content the onset of the first crystallization peak shifts toward higher temperatures.

Raman spectra of the series $\mathrm{A}$ of $25 \mathrm{ZnO}-25 \mathrm{SrO}-\mathrm{xB}_{2} \mathrm{O}_{3}-(50-\mathrm{x}) \mathrm{P}_{2} \mathrm{O}_{5}$ are shown in Fig. 1. The Raman spectra at the pure phosphate glass are characterized by two strong vibrational bands, the first one at $1181 \mathrm{~cm}^{-1}$ is ascribed to the symmetrical stretching vibrations $v_{\mathrm{s}}\left(\mathrm{PO}_{2}\right)$ groups in the metaphosphate chains, another strong band at $699 \mathrm{~cm}^{-1}$ is ascribed to the symmetrical stretching vibration $v_{\mathrm{s}}(\mathrm{POP})$ of the bridging oxygen atoms connecting neighboring $\mathrm{PO}_{4}$ tetrahedra; the broad band at $1268 \mathrm{~cm}^{-1}$ is assigned to the asymmetric stretching vibration of $\mathrm{v}_{\mathrm{as}}\left(\mathrm{PO}_{2}\right)$ of non-bridging oxygen in metaphosphate chains ${ }^{4}$.

With an increasing content of $\mathrm{B}_{2} \mathrm{O}_{3}$ replacing $\mathrm{P}_{2} \mathrm{O}_{5}$ in these glasses the strength of the two strong bands decreases and the position of the main band of $1181 \mathrm{~cm}^{-1}$ shifts to lower frequencies, whereas the other band splits into two weaker bands with the maximum at 670 and $746 \mathrm{~cm}^{-1}$. These changes are due to the depolymerization of the continuous phosphate network through the incorporation of $\mathrm{BO}_{4}$ and $\mathrm{BO}_{3}$ structural units into the phosphate chains. With a further increase in the $\mathrm{B}_{2} \mathrm{O}_{3}$ content the main high-frequency band shifts further to lower frequencies up to about $966 \mathrm{~cm}^{-1}$ at the glass with $10 \mathrm{~mol} \%$ of $\mathrm{P}_{2} \mathrm{O}_{5}$. At the pure borate glass this band is absent. We suppose that this band can be ascribed to the vibrations of isolated $\mathrm{PO}_{4}$ units in the structural network. This assignment is supported also by a close value of the $\mathrm{PO}_{4}{ }^{3-}$ anions in solutions ${ }^{7}\left(938 \mathrm{~cm}^{-1}\right)$, the difference in its position can be ascribed to a stronger vibrational coupling of the anions in the solid glass network in comparison with the solution. At the samples with a high $\mathrm{B}_{2} \mathrm{O}_{3}$ content there is a band at $769-775 \mathrm{~cm}^{-1}$. We assume that its assignment should be the same as in the borate glass with a similar $\mathrm{MO} / \mathrm{B}_{2} \mathrm{O}_{3}$ ratio ${ }^{8}$, where it is ascribed to the vibrations of six-membered borate rings containing $\mathrm{BO}_{4}$ structural units.

Infrared spectra of glasses of the compositional series A of $25 \mathrm{ZnO}-25 \mathrm{SrO}$ $\mathrm{xB}_{2} \mathrm{O}_{3}-(50-\mathrm{x}) \mathrm{P}_{2} \mathrm{O}_{5}$ are characterized by broad absorption bands, because perturbations 
due to neighbouring atoms affect the changes of dipole moments associated with IR active vibrational modes, causing multiple splitting and resulting in broad bands.

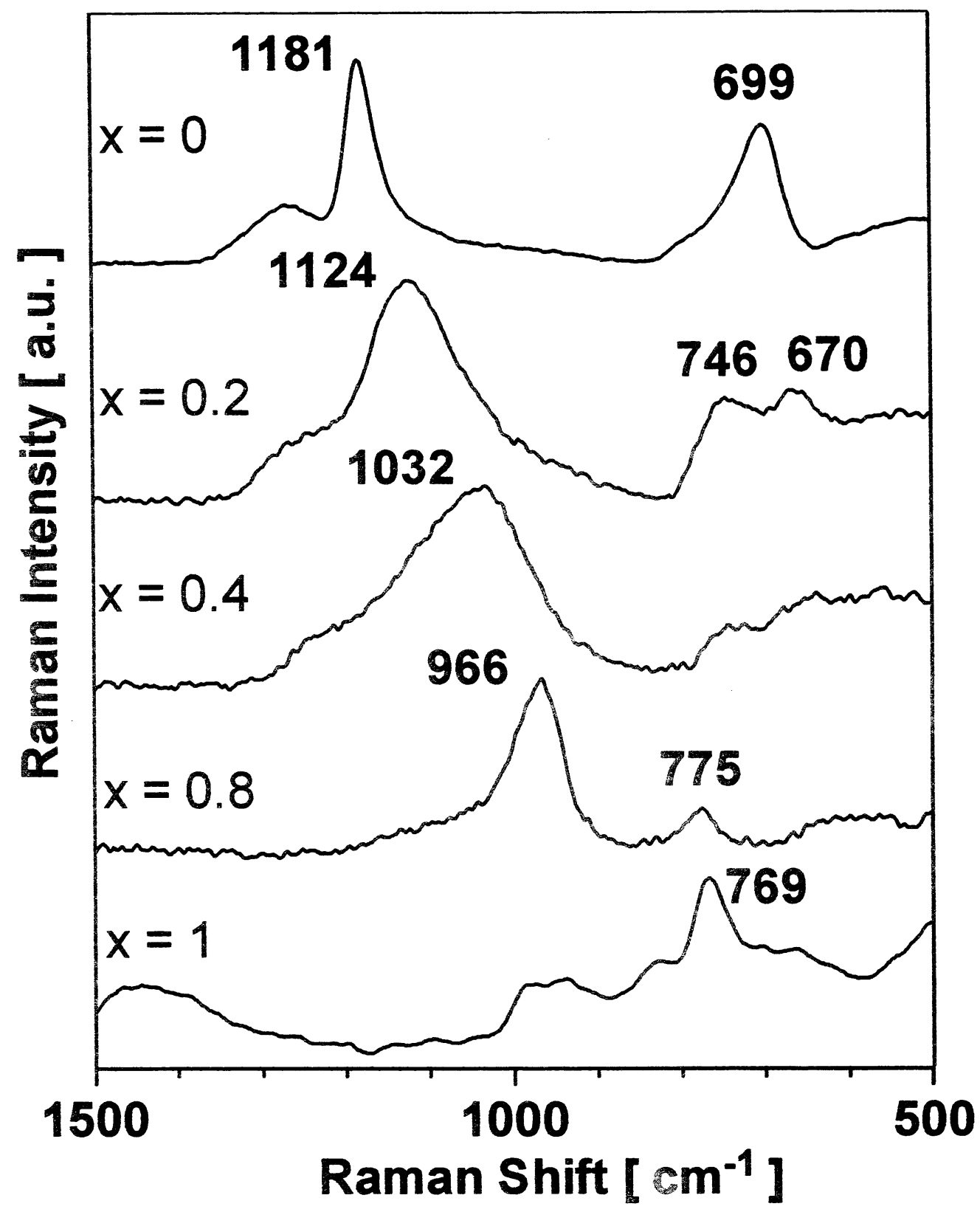

FIGURE 1. Raman spectra of the series of glasses $25 \mathrm{ZnO}-25 \mathrm{SrO}-\mathrm{xB}_{2} \mathrm{O}_{3}-(50-\mathrm{x}) \mathrm{P}_{2} \mathrm{O}_{5}$. 


\section{$\underline{\text { SUMMARY }}$}

The modification of zinc borophosphate glasses with the replacement of zinc atoms by strontium atoms changes some of the properties of the parent glasses of the $\mathrm{ZnO}-\mathrm{P}_{2} \mathrm{O}_{5}-\mathrm{B}_{2} \mathrm{O}_{3}$ system. An increase in $\mathrm{T}_{\mathrm{g}}$ shows that chemical bonding in the mixed $\mathrm{Sr}-\mathrm{Zn}$ borophosphate glasses is stronger than in pure zinc glasses.

It is interesting that at the glasses of the series B with $50 \mathrm{~mol} \% \mathrm{MO}$ the molar volume of the glass changes only a little when replacing up to $75 \%$ of $\mathrm{Zn}$ atoms by $\mathrm{Sr}$ atoms, in spite of that the volume of $\mathrm{Sr}$ atoms is nearly three time greater than that of $\mathrm{Zn}$ atoms. It means that the glass of $50 \mathrm{ZnO}-20 \mathrm{~B}_{2} \mathrm{O}_{3}-\mathrm{P}_{2} \mathrm{O}_{5}$ should have a relatively loose structure probably due to the metaphosphate-like chain sequences present in its structure. On the other side there is a substantial increase in the thermal expansion coefficient at these glasses more than twice the value found at the pure $\mathrm{ZnO}$ containing glass. An increase in the $\mathrm{Sr}$ content in the $\mathrm{SrO}-\mathrm{ZnO}-\mathrm{P}_{2} \mathrm{O}_{5}-\mathrm{B}_{2} \mathrm{O}_{3}$ glasses results also in a decrease of their tendency toward glass-formation.

\section{ACKNOWLEDGMENT}

The authors are grateful to Dr.M.VI $\square$ ek and Dr.M.Ve $\square$ e $\square$ a, from the University of Pardubice, for the Raman spectra and TMA measurements, respectively.

\section{REFERENCES}

[1] D.G. Grossman, and C.J. Phillips, J.Am. Ceram. Soc., 47, 471 (1964).

[2] J.M. Clinton and W.W. Coffeen, Ceram Bull, 63, 1401 (1984).

[3] R.K. Brow, J. Non-Cryst. Solids, 194, 267 (1996).

[4] R.K. Brow and D.R.Tallant, J. Non-Cryst. Solids, 222, 396 (1997).

[5] P.Mošner and L.Koudelka, Sci. Pap. Univ. Pardubice, Ser.A 4 75 (1998).

[6] L.Koudelka and P.Mošner, Mater. Chem. (in print).

[7] K.Nakamoto, Infrared and Raman Spectra of Inorganic and Coordination Compounds, Part A, J.Wiley and Sons, Inc., New York 1997, p. 199.

[8] E.I.Kamitsos, M.A.Karakassides, G.D.Chryssikos, J.Phys.Chem., 91, 1073 (1987). 